\title{
La tragedia de Xicohténcatl (1823) de José María Moreno Buenvecino: romanticismo mexicano emancipador
}

José Oscar Luna Tolentino

Luna Tolentino, J. Ó. (2021). La tragedia de Xicohténcatl (1823) de José María Moreno Buenvecino: romanticismo mexicano emancipador. Revista de Filología y Lingüística de la Universidad de Costa Rica, 47(2), e46562. doi: https://doi.org/10.15517/rfl.v47i2.46562

\section{(c) $\mathbb{P Q \Theta O}$}

Doi: https://doi.org/10.15517/rfl.v47i2.46562

URL: https://revistas.ucr.ac.cr/index.php/filyling/index 
Revista de Filología y Lingüística de la Universidad de Costa Rica

ISSN: 0377-628X

ISSN: 2215-2628

filyling@gmail.com

Universidad de Costa Rica

Costa Rica

\title{
La tragedia de Xicohténcatl (1823) de José María Moreno Buenvecino: romanticismo mexicano emancipador
}

\author{
Luna Tolentino, José Oscar \\ La tragedia de Xicohténcatl (1823) de José María Moreno Buenvecino: romanticismo mexicano emancipador \\ Revista de Filología y Lingüística de la Universidad de Costa Rica, vol. 47, núm. 2, e46562, 2021 \\ Universidad de Costa Rica, Costa Rica \\ Disponible en: https://www.redalyc.org/articulo.oa?id=33266553006 \\ DOI: https://doi.org/10.15517/rfl.v47i2.46562
}

\section{(c) $(1) \Theta(\Theta$}

Esta obra está bajo una Licencia Creative Commons Atribución-NoComercial-SinDerivar 3.0 Internacional. 


\title{
La tragedia de Xicohténcatl (1823) de José María Moreno Buenvecino: romanticismo mexicano emancipador
}

\author{
The Tragedy of Xicohténcatl (1823) by José María Moreno Buenvecino: Emancipatory Mexican Romanticism \\ José Oscar Luna Tolentino \\ Universidad Autónoma de Guerrero, Chilpancingo, México \\ 18522@uagro.mx \\ DOI: https://doi.org/10.15517/rfl.v47i2.46562 \\ Redalyc: https://www.redalyc.org/articulo.oa? \\ $\mathrm{id}=33266553006$
}

Did https://orcid.org/0000-0003-1524-2611

Recepción: 15 Julio 2020

Aprobación: 01 Septiembre 2020

\section{Resumen:}

En el presente artículo trabajaré las características estéticas que se desarrollan en la obra de teatro titulada: Xicobténcatl, publicada en 1823, por José María Moreno Buenvecino. Con base en los estudios especializados del Romanticismo por Isaiah Berlin, Antonio Candido, Cecilia Miranda Cárabes y Jorge Ruedas de la Serna, indicaré cuáles son los rasgos estéticos en esta pieza dramática. Su autor intentó reivindicar la figura de este héroe tlaxcalteca, en el sentido de buscar las raíces de nuestra mexicanidad, en esos primeros años de independencia de nuestra nación, enfocar y mostrar el sentido de "libertad de pensamiento y sentimiento". Con este trabajo pretendo realizar un aporte a las letras del siglo XIX, de nuestro país, ya que esta es una obra prácticamente desconocida que tuve la fortuna de transcribir del Fondo Reservado de la Biblioteca Nacional de México; espero que llegue a ser una obra un poco más conocida, y dado el caso se reedite, y sobre todo, se lleve a escena para su representación.

Palabras Clave: Xicohténcatl, México independiente, Romanticismo, Buenvecino, indigenismo.

\section{Abstract:}

In this article I will work the aesthetic characteristics in the play titled: Xicohténcatl, published in 1823, by José María Moreno Buenvecino. Based on the specialized studies of Romanticism by Isaiah Berlin, Antonio Candido, Cecilia Miranda Cárabes and Jorge Ruedas de la Serna, I will indicate what are the aesthetic features in this dramatic piece. Its author tried to vindicate the figure of this Tlaxcala hero, in the sense of looking for the roots of our Mexicanity, in those first years of independence of our nation, to focus and show the sense of "freedom of thought and feeling". With this paper I intend to contribute to the letters of the 19th century, in our country, because this is a practically unknown work that I had the fortune to transcribe from the Reserved Fund of the National Library of Mexico. I hope it will become a slightly more well-known work, and given the case, I hope it is reissued, and above all, it is brought to the stage for its representation.

KEYWORDS: Xicohténcatl, independent Mexico, Romanticism, Buenvecino, indigenism.

\section{INTRODUCCIÓN}

\author{
In memoriam: \\ Margarita Peña Muñoz \\ Jorge Ruedas de la Serna
}

La obra de teatro intitulada Xicohténcatl fue publicada en la Imprenta del Patriota, en la ciudad de Puebla en 1823. En un primer momento, se resguardó en la Biblioteca de Manuel María Romero, como se indica en el ex-libris; actualmente, se encuentra en el Fondo Reservado de la Biblioteca Nacional de México, la clasificación correspondiente es: ESM M862.2 MOR. X. El libro no se encuentra en muy buenas condiciones. En este acervo también se localizan los dos tomos de la poesía (publicados en 1822) del mismo autor, José María Moreno Buenvecino, que es un personaje poco conocido de nuestras letras dentro del siglo XIX. Esta pieza dramática escrita en verso se compone de 1507 versos, endecasílabos en su mayoría, con una rima asonante y dispar. Estructuralmente, está presentada en cinco actos "asimétricos": de tres escenas el primero 
(325 versos), el segundo (225 versos) y el tercero ( 414 versos); de seis escenas el cuarto ( 324 versos) y de cinco escenas el último (326 versos).

Decidí trabajar esta pieza dramática, porque Xicohténcatl ha sido un personaje paradójico, controversial y polémico a lo largo de la historia mexicana. La gran mayoría de los cronistas de indias refiere someramente a este personaje en sus obras: Diego Muñoz Camargo en la Historia de Tlaxcala (1892 versión), Fernando de Alva Ixtlilxóchitl en la Historia Chichimeca (1892 versión), Bernal Díaz del Castillo en la Historia verdadera de la conquista de la Nueva España (1939 versión) o Francisco López de Gómara en la Historia de la conquista de México (2007 versión). Por ejemplo, Antonio de Solís, en su Historia de la conquista de México (1995 versión), menciona sobre este tlatoani ${ }^{1}$ de Tlaxcala y de sus guerreros que: "Pasaba el ejército de cincuenta mil hombres (así lo confesaron ellos mismos), último esfuerzo de la república y de todos sus aliados, para coger vivos a los españoles y llevarlos maniatados, primero al sacrificio, y luego al banquete" (de Solís, 1995, p. 129). Por su parte, Bernal Díaz del Castillo refiere que este señor principal no logró vencer a Cortés por no tener el apoyo de los demás "generales o capitanes" (así los nombra él) de Tlaxcala:

Y como el Xicotenga (sic) no era obedecido de dos de sus capitanes, y nosotros les hacíamos gran daño, que les matábamos muchas de sus gentes, las cuales encubrían, porque como eran muchos, en hiriéndolos a cualquiera de los suyos luego lo apañaban y lo llevaban a cuestas, así en esta batalla como en la pasada, no podíamos ver ningún muerto (Díaz del Castillo, 1939, p. 230).

Se sabe que combatió a los españoles entre el 1 y el 23 de septiembre de 1519 y, a pesar de que se presupone que estuvo apoyando a Cortés, los hechos indican que: "Axayacatzin Xicohtencatl murió ajusticiado, pues lo mandó ahorcar Cortés por consentimiento de la República de Tlaxcala (sic), estando en Tetzcuco (sic) sobre la guerra de México" (Muñoz Camargo, 1892, p. 233). En tiempos recientes, Alejandro González Acosta, en el capítulo segundo de su libro El enigma de Jicotencal (1997), refiere mayores datos históricos de este atractivo y singular personaje tlaxcalteca.

En este sentido, Xicohténcatl es importante porque corresponde a un emblema de resistencia en contra de la conquista para nuestra nación; diversos espacios públicos ostentan su nombre: parques, escuelas, calles; la antigua casona del Senado de la república también lleva su nombre. Empero, es una figura ambigua, pues no se ha reconstruido íntegramente como personaje histórico ${ }^{2}$. En la ficción literaria tampoco se ha delineado cabalmente. Son diversas las representaciones que se han hecho al respecto, tal vez la más significativa sea la novela que se le atribuye a José María Heredia, Jicotencal (1826), obra que se define como "narrativa de ideas", en que se expone un programa político con tópicos como el independentismo social, liberal y filosófico (González Acosta, 1997).

En esta obra de teatro que nos atañe, históricamente, Xicohténcatl participa previo a la caída de la gran Tenochtitlán, ese tiempo en que Cortés preparó los bergantines, armamentos y tropas para sitiar y consumar la conquista, ocurrida el 21 de agosto de 1521. Moreno Buenvecino aprovechó la visión decimonónica que le permitió la distancia temporal, para manifestar el orgullo patriótico en ese momento de escritura; es importante resaltar que publica esta obra de teatro dos años después de la Independencia. La consigna o motivación era erigir héroes autóctonos para celebrar la emancipación política del naciente país que, en ese entonces, había mudado por segunda vez de forma de gobierno (República), desde el primer intento fallido por implantar el Imperio (meses antes, en febrero de 1822, había colapsado la farsa pomposa que proclamó a Agustín I como el emperador).

Desafortunadamente, acerca de la vida de Moreno Buenvecino pocos datos se tienen. Nos informa Francisco Pimentel, el primer crítico que registra y refiere su obra, que era originario de Querétaro y fue sobrino del presbítero Dr. José Demetrio Buenvecino, quien adquirió la Imprenta Liberal de Troncoso Hnos. en 1821. Pimentel (1885) menciona que Moreno Buenvecino publicó entre los años de 1822 y 1828 las siguientes obras: las tragedias Laura, México o el amor a la libertad y Xicoténcatl, y el drama alegórico América mexicana libre. No obstante, Pedro Henríquez Ureña, en la Antología del Centenario (1985) nos da mayores 
referencias de este autor, al escribir una bibliografía de este bachiller en cánones y completar con mayor precisión las referencias mencionadas:

Odas a la libertad mexicana. Puebla, Imprenta Liberal, 1822.

Laura. Tragedia en cuatro actos y en verso. Puebla, Imprenta Liberal, 1822.

Mixcoac. Tragedia en tres actos y en verso. Puebla, Imprenta Liberal, 1822.

América mexicana libre, drama alegórico en dos actos y en verso. Puebla, Imprenta Liberal, 1823.

Xicobténcatl, Tragedia en cinco actos y en verso. Puebla, Imprenta Liberal, 1827.

Adela o la constancia de las viudas. Ópera jocoseria en dos actos. Puebla, Imprenta Liberal, 1823.

(Henríquez Ureña, 1985, p. 893).

Como se puede reparar en los títulos de las obras de Moreno Buenvecino, en la mayoría intentó construir una apología de figuras con cariz republicanas o nacionalistas. Odas a la ya denominada República Mexicana, personajes que se yerguen como símbolos representativos de la mexicanidad que se quería mostrar y establecer. Sin duda alguna es un autor que merece ser rescatado y que sus obras se conozcan y estudien para tener presente esa misión patriótica y nacionalista. Ganó cierta notoriedad por una oda anacreóntica dedicada al pulque que repercutió en su época y fue motivo de referencia por ese sentir de lo "mexicano": “¡Blanco, espumoso pulque! / ¡Consolador festivo! / Ven, y amigo refresca / mi labio desequido // Por ti el duro trabajo / del bochornoso estío / soporta con paciencia / y aún con placer el indio" (Henríquez Ureña, 1985 p. 337).

\section{Atisbos estéticos en Xicohténcatl}

La sociedad empieza por cantar lo que sueña,

después refiere lo que hace,

y al fin describe lo que piensa

(Víctor Hugo, 1981, p. 10).

Esta pieza dramática se puede considerar como un embrión de estética romántica que, como se sabe, se ingresa en una aporía cuando se intenta definir qué es el Romanticismo estéticamente, ya que se trata de un fenómeno en suma complejo y múltiple; las apreciaciones que se han realizado son solo eso: un repertorio inmenso de aproximaciones. Como bien ha señalado Isaiah Berlin, autor de Cuatro ensayos para la libertad (1988), tanto para los pietistas germanos como para todos los cultivadores posteriores de este sentir artístico, las impresiones serán variadas y complicadas de definir:

El romanticismo es lo primitivo, lo carente de instrucción, lo joven. Es el sentido de la vida exuberante del hombre en su estado natural, pero también es la palidez, fiebre, enfermedad, decadencia, la maladie du siècle. [...] Es la confusa riqueza y exuberancia de la vida, fülle des Lebens, la multiplicidad inagotable, la turbulencia, la violencia, el conflicto, el caos, pero también es la paz, la unidad con el gran «yo» de la existencia, la armonía con el orden natural, la música de las esferas, la disolución en el eterno espíritu absoluto (Berlin, 2000, p. 37).

Y así podríamos proseguir en las apreciaciones y cada autor tendría su propia concepción con respecto al Romanticismo, creadores de la talla de Goethe, Nietzsche, Heine, Taine, Schelgel, Scott, Victor Hugo, Stendhal, Bécquer, recrean y representan esta estética de manera muy particular. En este sentido, para comprender esa complejidad, el romanticismo que se practicó en el continente americano se desarrolló de manera tardía, varias décadas después de las manifestaciones alemanas, inglesas, francesas y españolas, en las que no hace falta ahondar por el momento para los propósitos de este trabajo. No obstante, baste referir que en el Diccionario de términos literarios de Demetrio Estébanez Calderón (1999), aparecen los siguientes datos sobre el Romanticismo en Hispanoamérica: 
Entre los temas más frecuentemente abordados figuran el indianismo e indigenismo, la exaltación de la naturaleza y del pasado nacional de cada país, el costumbrismo; y, en cuanto los géneros, los preferidos son la poesía y la novela: histórica, de costumbre y social-política (p. 957) ${ }^{3}$.

En México, ya con anterioridad algunos letrados humanistas habían buscado lo nacional en el pasado; por ejemplo, los jesuitas Francisco Javier Alegre en la Historia antigua de México (1780), Francisco Javier Clavijero en sus Disertaciones (1780) o Rafael Landívar con su Rusticatio mexicana (1871). A inicios del siglo XIX, reforzando esa orientación de buscar literariamente lo nacional en lo indígena, será curiosamente una novela escrita por Chateaubriand, Atala (1801), la que marcará la pauta. En este sentido, serán varias las obras a lo largo del continente que buscaron sus raíces nacionales en el pasado precolombino o en el mestizaje diferenciado de lo europeo: Muñoz, visitador de México (1838), Cecilia Valdés (1839), El Matadero (1840), Facundo (1845), El Gíbaro (1849), Martín Fierro (1872), Cumandá (1879). Estos libros nos permiten vislumbrar la complejidad no solo temática, sino cronológica del romanticismo hispanoamericano.

Pero ¿cuáles podrían ser sus características medulares? Nos ceñiremos a la siguiente propuesta: la gran bandera de este movimiento es la Libertad, difuminada en una tríada de aspectos, esto es: 1) libertad de pensamiento, 2) libertad de sentimiento y 3 ) libertad de expresión. Por el momento, me interesa enfocar los dos primeros aspectos que se perciben de manera nítida; en el primero, por ejemplo, en el caso de América Latina, con obras claves de los libertadores ingentes como son: La carta a Jamaica (1815) del prócer Simón Bolívar y Nuestra América (1891) del gran maestro José Martí; en el caso de México hay varios textos, pero el más emblemático puede ser Los sentimientos de la Nación (1813) de José María Morelos y Pavón. En el segundo, también tenemos varias obras referenciales como son las siguientes: Iracema (1865) de José de Alencar, Aves sin nido (1889) de Clorinda Matto de Turner o en México, Netzula (1837) de José María Lacunza o Clemencia (1869) de Ignacio Manuel Altamirano ${ }^{4}$.

Como se puede percibir con las referencias pasadas, al intentar encuadrar temporal o temáticamente la estética romántica en nuestra literatura latinoamericana resulta complejo acotarla y definirla. Sin embargo, en el caso de nuestro país, ya se han realizado estudios discernidos en tres momentos, los cuales intentaré sondear dentro del "Primer romanticismo mexicano". Este se puede enfocar históricamente en dos movimientos literarios fundamentales: la Academia de Letrán (1836) y el Liceo Hidalgo (1849): "En México entre luchas fratricidas, intereses encontrados e invasiones extranjeras se aviva la idea de libertad, característica esencial de la escuela romántica" (Miranda Cárabes, 1998, p. 20). En esa idea de Libertad que señala acertadamente Celia Miranda Cárabes se desarrolla un patriotismo que intentó buscar lo propio, rastrear nuestras raíces en el pasado, en lo arrebatado por los españoles. En este periodo histórico enmarcado por estas dos asociaciones de escritores humanistas, se presenta una pléyade de autores que es motivo de orgullo para México, entre ellos baste referir, por un lado, a los siguientes que en Letrán se reunieron y debatieron: Andrés Quintana Roo (1787-1851), Manuel Eduardo Gorostiza (1789-1851), Manuel Carpio (1791-1860), José Joaquín Pesado (1801-1861), Fernando Calderón (1809-1845), José María Lacunza (1809-1869), José María Lafragua (1813-1875), Ignacio Rodríguez Galván (1816-1842), Ignacio Ramírez "El Nigromante" (1818-1879), Guillermo Prieto (1818-1897). Por otro lado, a quienes en la palestra del Liceo se congregaron: Francisco Zarco (1829-1869), José Tomás de Cuellar (1830-1894), Ignacio Manuel Altamirano (1834-1893), Manuel M. Flores (1838-1885). Ante estos grandes autores es comprensible que el autor de Xicohténcatl no descollara como correspondía. Estas personalidades se desarrollaron en una faceta histórica que consistía principalmente en independizarse en todos los sentidos posibles de la Colonia. Esta postura se presenta en el devenir de las grandes naciones del continente y, como bien menciona el maestro Antonio Candido en el caso del Brasil, los letrados tuvieron una especie de misión, un compromiso ético y social:

[...] la literatura fue considerada un esfuerzo constructivo más amplio, detonando el propósito de contribuir para la grandeza de la nación. Se mantiene durante todo el Romanticismo este sentimiento de deber patriótico, que elevaba a los escritores 
no sólo a cantar a su tierra, sino a considerar sus obras como contribución al progreso. Construir una «literatura nacional» es afán, casi lema, proclamado en los documentos del tiempo hasta volverse enfadosos (Candido, 2014, p. 326).

En el caso de José María Moreno Buenvecino, como veremos en el análisis, podremos percibir esa orientación romántica libertaria de cariz patriótica que buscó transmitir en la mayoría de sus composiciones literarias, y que en el caso específico de esta obra dramática que nos corresponde, seguramente se representó en escena en la ciudad de Puebla de los Ángeles, para intentar llegar a un mayor número de receptores. En los personajes principales y protagónicos se vislumbrará ese sentir romántico de trascender que el maestro Jorge Ruedas de la Serna ha sintetizado adecuadamente: "El perfecto romántico es aquel que desafía al mundo y a la sociedad y triunfa sobre sus normas y designios. La racionalidad no radica en las leyes que gobiernan al universo, sino más bien en esa fuerza inspirada del individuo" (Ruedas de la Serna, 1998, p. 54).

Xicohténcatl junto a su amada Teutila sintetizarán y representarán simbólicamente ese espíritu romántico de los antiguos mexicanos que buscaron la libertad en todos sus sentidos, ante las salvajes batallas ejecutadas por los sanguinarios conquistadores; esa actitud de rebelión y no sometimiento se matiza y se potencializa al dar la vida por estos ideales, con tal de no dejarse vencer por el enemigo: esa será la fuerza, ese será el estruendo de liberación, como veremos a continuación en esta pieza dramática ${ }^{5}$.

\section{XicohtÉnCATL: LIBERTAD DE PENSAMIENTO Y SENTIMIENTO}

La vida sin honores muerte infame.

Morir con gloria es el mayor trofeo,

Es el triunfo mayor, que un hombre honrado

Puede lograr en este triste suelo.

(Moreno Buenvecino, 1823 p. 5).

La anterior frase engloba el tenor de la composición. El mensaje de la representación es conciso: "preferible morir de pie en combate que humillarte de rodillas ante el enemigo". Si bien estos personajes de ficción se recrean a partir de hechos históricos, como hemos visto, en la representación ficcional se pueden vislumbrar ciertos sentidos hiperbólicos en los caracteres de su composición: Xicohténcatl y Teutila signan pureza de sentimientos, virtudes en sus acciones y, sobre todo, la honra que conservan al sacrificar su vida. En contraparte, Hernán Cortés y sus soldados simbolizan esa retórica de la violencia, las armas, los cañones y los caballos que son los instrumentos con los cuales se impusieron con soberbia y prepotencia: “iQué!, ¿̇no sabe ese bárbaro insensato / Que al solo nombre España el Orbe tiembla? / ¡Un indio contra España! ¡Contra Carlos / Augusto emperador! ¡Contra el gran César, / Que es señor de Alemania, de la Italia, / De Flandes, de...!" (Moreno Buenvecino, 1823, p. 15). La obra, como he mencionado, está compuesta de cinco actos: la trama se desarrolla en la confrontación, originarios contra conquistador; es simple, pero se entiende, ya que el tesón es de tinte nacionalista y corresponde al ideario de resaltar lo autóctono. Evocar la grandeza tlaxcalteca, del pueblo mexicano si no se hubiera dado la traición, idealizándola: "Será un pueblo de hermanos: sus gobiernos, / Aunque distintos, en alianza eterna / Unidos vivirán: abrazo estrecho / Dará el Azteca al Tlaxcales valiente, / Y el Texcocano al Chichimeca fiero: / Todo paz, todo holgura, quietud todo" (Moreno Buenvecino, 1823, p. 13) ${ }^{6}$.

En ese primer acto aparecen los personajes principales, los esposos Teutila y Xicohténcatl, que son acompañados por el padre de ella, Teutile; Cóyotl, el guerrero texcocano; y Nopáltzin que en esta ocasión será la figura que ejecute la traición (se refiere la ausencia de un guerrero chichimeca que nunca aparece en escena y tiene que ver con un dato histórico, ya que era el enemigo de nuestro héroe) ${ }^{7}$. Además de la resistencia de no dejarse conquistar bélicamente, existe un asunto primordial en la trama, Teutila intuye la traición y sabe que Cortés está encaprichado no solo por matar a su esposo, sino por poseerla:

No puedo sofocar la llama intensa 
Que hizo nacer en mí su rostro hermoso.

A la luz de sus ojos mis potencias

Se obscurecieron: resistí, y en vano,

Que de mi resistencia al fin triunfó ella.

Me declaro rendido, y la india altiva

Me repele: el amor, y mi soberbia

Herida me sostienen: firme insisto;

Pero mayor de ella es la firmeza

(Moreno Buenvecino, 1823, p. 20).

El autor presenta a Teutila para que descolle en la trama, ya que es caracterizada como una mujer que posee el don de la palabra, además de que es visionaria y prudente. Así que cuando caen en la emboscada a la que los lleva Nopáltzin, ella intercede para que no sean ejecutados en el acto por Cortés, implora por la vida de ambos, a lo cual Xicohténcatl repele humillado: "Calla, hembra vil, degenerada estirpe / De Teutile: tu llanto y plegaria / Me son más crueles que la muerte misma: / Pues baldonan y humillan a Tlaxcala” (Moreno Buenvecino, 1823, p. 31). Como podemos ver, la pareja se sublima en las acciones, ya que no caen ante la presión psicológica, en una primera instancia, y posteriormente tampoco sucumben a la violencia bélica del conquistador. En este sentido, se puede enfocar esa estética romántica de libertad: “[...] un hombre que simplemente acepta lo que la vida o la naturaleza le ofrece está muerto. Y esto es no solamente aplicable a los hombres sino también a las naciones" (Berlin, 2000, p. 125).

Cortés, quien es acompañado por Diego Ordaz intenta a toda costa imponerse, primero por medio de la palabra, con tretas propias a la milicia y al no lograr su cometido, intenta imponerse con violencia, a lo que Teutila firme le responde: "No, no es la muerte, esposo, lo que temo, / Amo, como tú mismo, a nuestra patria, / Y estoy pronta por ella a dar vida: / Nada por mi peligro me acobarda" (Moreno Buenvecino, 1823, p. 25). Teutila en el sentido alegórico se contrapone a otro personaje histórico que no aparece en esta obra, pero que forma parte del imaginario colectivo de nuestra nación: la Malinche. El ideal prevaleciente en aquella época independentista era que la "Patria es primero", como pronunció Vicente Guerrero escasos cuatro años atrás, y la traición a este ideal es la manifestación más ruin. Por tal motivo se entiende que ambos personajes de ficción prefieran trascender el plano físico sin dejarse vencer por el conquistador, el sentido romántico en esta pareja de esposos es nítidamente manifiesto, son ese tipo de personajes románticos que han sido tocados por la Providencia; como ocurrió con el emblemático Edmundo Dantés, en el Conde de Montecristo, quien nunca se dejó vencer ante toda adversidad:

Así es como nuestro héroe queda investido por ese gran poder que ejercerá fielmente en toda la historia. Se prefigura ahí la idea de la Providencia romántica, que habrá de manifestarse en mil formas como recurso privilegiado del escritor para estremecer al lector. Será la explicación última de la fatalidad que en el momento menos esperado hace nacer el drama y torcer el destino del personaje (Ruedas de la Serna, 2006, p. 151) ${ }^{8}$.

El discurrir al respecto se desenvuelve en el momento climático de la representación; Xicohtencatl le hace ver a Cortés que si bien todas las naciones del altiplano seguramente se arrodillarán ante su figura y que a pesar de que su empresa es de muerte y destrucción: "Vertiendo ríos de sangre; cayó a tierra / Al duro bote de mi férrea lanza. [...] Sobre áureas andas, que en sus hombros llevan / Solícitos esclavos obedientes" (Moreno Buenvecino, 1823, p. 19), todas sus infamias en nombre de Dios, nada le garantizarían que disfrutará posteriormente del triunfo, tanta muerte a su paso, de nada le serviría. José María Moreno Buenvecino se da la licencia poética de poner en los labios de este ser de ficción el sentir romántico de su época, ese orgullo independentista: "Quizá en España morirás sin gloria, / De tu altivo monarca desdeñado, / Gozando otros el fruto de tus obras...” (Moreno Buenvecino, 1823, p. 50).

Esta visión decimonónica se hace manifiesta en esta última elucubración y, de forma oblicua, se muestra la visión de que la nueva nación debía responder a ese momento histórico y afrontar con carácter la defensa de su territorio. Nunca sucumbir ante el enemigo ${ }^{9}$. No obstante, es importante reparar en que, aun cuando Cortés 
se amotinó durante varios meses en territorio tlaxcalteca, difícilmente se podía desarrollar en la "realidad" este tipo de diálogo entre ambos personajes. En esta línea, retomando el sentido alegórico ya referido, en voz de Xicohténcatl el poeta alude a la mezcla entre las dos culturas; menciona que la nueva raza que se conformará va a devolver la libertad a los originarios de estas parcelas. Además, la comunidad a la que va dirigida la representación es muy nítida, los receptores pertenecen a su época y a épocas posteriores:

\author{
Y en esta previsión mi alma se goza. \\ Los hijos de Pelayo en matrimonio \\ Con las anahuacensas amorosas \\ Se unirán, procreando noble raza \\ De hombres valientes, que con mano heroica \\ Troncharán los robustos eslabones \\ De sus cadenas \\ (Moreno Buenvecino, 1823, p. 40).
}

Esta premonición es importante, la reflexión al respecto es puntual y acorde a la que se plasmó también en el siglo XX, con Ermilio Abreu Gómez en la "Guerra de castas" de la obra clásica Canek; en ella evoca siglos pasados, desarrolla el caso mayanse y pone en voz del personaje principal tales reflexiones; de esta forma, enfoca ese racismo biológico y cultural que tanto daño ha provocado no solo a México, sino a diversos pueblos o naciones a nivel mundial. Así pues, el mestizaje inminente e inevitable concebirá una población que se nutrirá de los atributos de las culturas, y quitará esa visión polarizada en múltiples sentidos:

Canek dijo:

-El futuro de estas tierras depende de la unión de aquello que está dormido en nuestras manos y de aquello que está despierto en la de ellos. Mira ese niño tiene sangre india y cara española. Míralo bien: fíjate que habla maya y escribe castellano.

[...] No es de la tierra ni del viento. En él, la razón y el sentimiento se trenzan (Abreu Gómez, 2014, p. 54).

Antonio Candido ha referido acertadamente sobre este sentir romántico que se muestra en las obras de esta estética, la cual evidencia el ímpetu libertador de sus creadores; esa misión, esa ética social, ya citada líneas arriba; parafraseo al maestro:

1) Tener una literatura independiente.

2) Sus características deben ser del medio, de las razas y de las costumbres del país.

3) Los indios son los personajes más legítimos, investigar sus características poéticas y tomarlos como tema.

4) Más allá de los indios, la descripción de la naturaleza y las costumbres son criterios de identificación nacional.

5) La religión como elemento indispensable de la nueva literatura.

6) Es imperativo conocer la literatura nacional del pasado para saber qué obras abrieron brecha en las corrientes actuales. (Candido, 2014).

Moreno Buenvecino sabía o intuía este ideario romántico que podemos ver y analizar en esta pieza dramática, el cual es acorde a las inquietudes parafraseadas. En el desenlace se genera esa tensión en la que se vislumbran algunas de estas características. En la libertad de pensamiento y sentimiento Teutila increpa a Hernán Cortés: "No soy la esposa yo del héroe bravo / Xicohtencatl, la gloria de Tlaxcala, [...] No: que en él muera; pero su honor brille / Con mayor luz que la que ostenta el astro / Del día” (Moreno Buenvecino, 1823, p. 37). Xicohténcatl y Teutila ideológicamente nunca se someten, como hemos presenciado, y en cuanto a sus sentimientos hay una templanza que intenta desdecir lo referido por los cronistas de indias ${ }^{10}$.

En ese sentido, en la escena final, a punto de ser asesinado su esposo, Teutila planea matar en ese momento a Cortés, pero falla y es herida en el intento; Xicohténcatl encadenado sufre y nada puede hacer, pero presencia y escucha el discurso de su amada, quien al enterarse de que será torturada y tendrá una muerte terrible, decide quitarse la vida ella misma; le grita al conquistador que ni siquiera ese gusto le dará y le pide a su amor que la imite, que se quite él mismo la vida y se golpee contra una roca que está a su lado: 


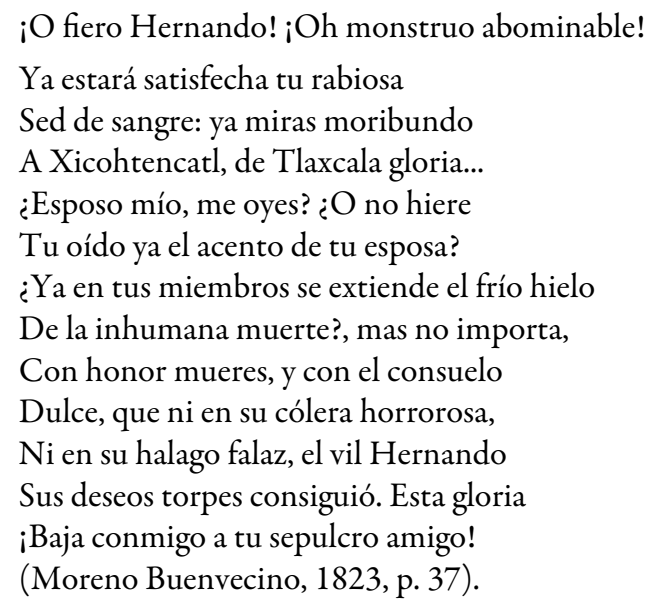

Desafortunadamente, no hay indicios de que esta obra se haya llevado a escena. En un estudio sobre el teatro de esa época, 1820, Nicolás Rangel lamenta que no haya datos: "En este año y en el siguiente, la vida teatral fue, con pocas variantes, igual a las anteriores en cuanto a las representaciones; no se registraron estrenos de nuevas piezas ni acontecimientos de que tengamos noticia digna de relatarse" (Rangel, 1985, p. 429). Tal vez sea por el centralismo como forma de gobierno que no se conserven estos datos.

Como he intentado mostrar con este nimio análisis, esta obra de teatro merece estar presente en nuestras letras, no solo mexicanas, sino latinoamericanas; en primer lugar, por la época, pues dicha conquista fue vivida por la gran mayoría de nuestras actuales naciones; en segundo lugar, por la propuesta de reescribir el pasado y reivindicar la lucha y resistencia de nuestros antepasados, para erigir héroes propios que son muy necesarios en el tiempo actual.

\section{Conclusiones}

Como se puede vislumbrar, aún hace falta reconstruir más cabalmente la figura de Xicohténcatl, para dar una versión más fidedigna de este personaje que es emblemático en la historia de México (trabajo de bastante aliento que implicaría un esfuerzo más profundo de investigación). En ese sentido, se podría realizar un ensayo buscando analogías y diferencias entre la versión de Moreno Buenvecino y la de José María Heredia. En el plano de las ideas propuestas existen bastantes preguntas que quedan por responder, por ejemplo: ¿Por qué Heredia publica su obra en Filadelfia, allende nuestro país y además sin atribuirse la composición? La obra de Moreno Buenvecino es poco anterior, el cuestionamiento sería: ¿existe plagio o es una mera coincidencia que ambos autores se enfocaran en el mismo personaje?

José María Moreno Buenvecino en los inicios del siglo XIX reivindica la figura de este legendario guerrero tlaxcalteca, para mitificarlo como un héroe que necesitaba la naciente República Mexicana; la paradoja es que, penosamente, en la actualidad muchos siguen tachando como traidores a los tlaxcaltecas. En este tenor, ojalá que este trabajo tenga un poco de resonancia, y logre parte de sus intenciones, esto es: que se tome en cuenta esta obra de teatro, ya que sería un gran aporte cultural e histórico; y sobre todo, que sea llevada a escena, que se represente en los teatros municipales de las principales ciudades de México. Obviamente, debe hacerse una adaptación libre y que se escuche el mensaje de este autor en las fechas conmemorativas de la Independencia, para que los jóvenes conozcan a estos personajes emblemáticos (por mi parte, intentaré que sea publicada y asimismo que se representen algunos de los actos).

Para finalizar, no quiero dejar pasar la oportunidad de compartir que tuve la fortuna de estar en el proyecto de investigación de mi mentor, el doctor Jorge Ruedas de la Serna, sobre la formación de la literatura nacional (1805-1850), en el cual conocí la obra de Moreno Buenvecino ${ }^{11}$. En ese entonces, estudiaba la maestría y presenté una versión preliminar de este trabajo en una ponencia en las jornadas de la Cátedra Juan Ruiz de Alarcón, a cargo de la doctora Margarita Peña, en mi Alma Mater, la UNAM. A ambos dedico este humilde 
José Oscar luna Tolentino. La tragedia de Xicohténcatl (1823) de José María Moreno Buenvecino: rom...

texto, mis caros maestros que me inculcaron el amor y aprecio por las letras mexicanas de los siglos de la Colonia y la Independencia.

\section{Bibliografía}

Abreu Gómez, E. (2014). Canek. México: Editores Mexicanos Unidos.

Berlin, I. (2000). Las raices del romanticismo. Madrid: Taurus.

Candido, A. (2014). Formación de la literatura brasileña. Momentos decisivos 1750-1880. (Vol. 3). México: UNAM.

De Alva Ixtlilxóchitl, F. (1892). Capítulo LXXXIV. En A. Chavero (Ed.), Obras históricas (Tomo 2, pp. 369-374). México: Secretaría de Fomento.

De Solís, A. (1995). Historia de la conquista de México. México: Espasa-Calpe.

Díaz del Castillo, B. (1939). Historia verdadera de la conquista de la Nueva España. México: Editorial Pedro Robredo.

Estébanez Calderón, D. (1999). Diccionario de términos literarios. Madrid: Alianza Editorial.

González Acosta, A. (1997). El enigma de Jicotencal. México: UNAM / Gobierno del Estado de Tlaxcala.

Henríquez Ureña, P. (1985). José María Moreno. En J. Sierra (Coord.), Antología del Centenario (Tomo 2, pp. 336-342). México: UNAM.

Hugo, V. (1981). Cromwell. México: Editores Mexicanos Unidos.

León-Portilla, M. (2009). La visión de los vencidos. México: UNAM.

López de Gómara, A. (2007). Historia de la conquista de México. Venezuela: Biblioteca Ayacucho.

Martínez, J. L. (2000). Unidad y diversidad. En C. Fernández Moreno (Coord.), América Latina en su literatura (pp. 73-92). México: Siglo XXI.

Martínez Luna, E. (2009). Bicentenario del Diario de México. Los albores de la cultura letrada 1805-2005. México: Universidad Nacional Autónoma de México.

Miranda Cárabes, C. (1998). La novela corta en el primer Romanticismo mexicano. México: UNAM.

Moreno Buenvecino, J. M. (1823). Xicohtencatl. Tragedia en cinco actos. Puebla: Imprenta del Patriota.

Monsiváis, C. (2009). La herencia oculta de Guillermo Prieto. En V. Quirarte (Coord.), Guillermo Prieto. La patria como oficio (pp. 467-490). México: Universidad Nacional Autónoma de México / Fundación para las Letras Mexicanas / Fondo de Cultura Económica.

Muñoz Camargo, D. (1892). Historia de Tlaxcala. México: Secretaría de Fomento.

Ozuna Castañeda, M. (2012). Estudio preliminar. En M. Ozuna Castañeda (Ed.), Manuel Payno. Todo el trabajo es comenzar (pp. 13-38). México: Universidad Nacional Autónoma de México / Fundación para las Letras Mexicanas / Fondo de Cultura Económica.

Pimentel, F. (1885). Historia crítica de la poesía y de las ciencias en México, desde la Conquista a nuestros días. México: Librería de la Enseñanza.

Rangel, N. (1985). Teatro. En J. Sierra (Coord.), Antología del Centenario (Tomo 2, pp. 420-429). México: UNAM.

Ribeiro, D. (1972). Configuraciones. México: Secretaria de Educación Pública.

Ruedas de la Serna, J. (1998). La novela corta de la Academia de Letrán. En C. Miranda Cárabes (Ed.), La novela corta en el primer Romanticismo mexicano (pp. 53-72). México: UNAM.

Ruedas de la Serna, J. (2006). De la venganza, a propósito de un ensayo de Antonio Candido. Anuario del Colegio de Estudios Latinoamericanos, 1, 143-153.

Zorrilla, J. (2000). México y los mexicanos. México: Consejo Nacional para las Culturas y las Artes. 


\section{Notas}

1 El tlatoani era el señor principal, traducido del náhuatl al castellano como 'gobernador' o 'emperador', este era el líder de la ciudad que gobernaba. En el valle de Anáhuac, en la llamada Triple alianza, se unían estos guerreros para combatir. En el caso de Tlaxcala, se daban estas uniones entre las cuatro comunidades más importantes. En el Lienzo de Tlaxcala, se describe que en ese momento histórico estos cuatro señores principales eran: Mazicahtzin, Xicohtencatl, Tlahuexolotzin y Chimalpopoca (Muñoz Camargo, 1892).

2 Tal confusión se debe a que no es un Xicohténcatl, son dos, el padre, denominado como el huébuetl (viejo, aunque la traducción más apegada sería ‘abuelo’ o ‘sabio’) y el joven, que Muñoz Camargo nombra adecuadamente, en el Lienzo de Tlaxcala, como Axayacatzin (diminutivo de Axayácatl, tlatoani azteca) (Muñoz Camargo, 1892).

3 Reforzando la idea de que es más una obra del primer romanticismo mexicano, tomo como sendero la propuesta de Darcy Ribeiro en su obra Configuraciones (1972), donde indica cuatro posibilidades en la configuración de los pueblos en América: 1) Testimonio, 2) Nuevos, 3) Trasplantados y 4) Emergentes. Los primeros serán aquellos que lograron, después de los siglos de colonización, tener testimonios de los originarios que la padecieron, como México o Perú, por ejemplo; los segundos serán aquellos países que tendrán la mezcla de los europeos con los originarios, pero sobre todo con los esclavos africanos que poblaron estos territorios, como varias islas del Caribe. Sobre estos dos grupos refiere el brasileño: “[...] por ser sociedades fundadas y moldeadas por la voluntad del núcleo colonizador; y por haber sido intencionalmente para servir a intereses y objetivos exógenos" (Ribeiro, 1972, p. 79). Al disminuir ese yugo, obviamente, se buscó la raíz de lo nacional que fue "destruido" por los conquistadores.

4 José Luis Martínez en su obra: La emancipación literaria de México (1955), estudió esa postura que tomaron varios escritores de ese siglo, al respecto menciona: "En el primer tercio del siglo la literatura va a adquirir una intensa carga ideológica que la haría participar, de manera sobresaliente, en el complejo proceso de elaboración cultural. Ninguna otra empresa posterior llegaría a adquirir la fuerza que tuvo, en América Latina, aquella que se propuso conquistar nuestra emancipación literaria, porque su lucha era enaltecer la existencia misma de la expresión literaria propia de América” (Martínez, 2000, p. 75).

5 El escritor español José Zorrilla que estuvo en México en ese periodo inmediatamente posterior a la Independencia, nos regaló sus apreciaciones en una serie de cartas que se resguardan en el libro: México y los mexicanos. La gran mayoría de intelectuales liberales cambiaron de paradigma y España con toda su cultura quedó al margen y su obviamente "atacada", al respecto menciona: "En 1821 la literatura mexicana fue naturalmente arrastrada por el torbellino revolucionario que consumó su independencia, y los poetas se lanzaron a la arena política entonando himnos a la libertad. [...] en mi naturaleza de español no cabe decorosamente la alabanza de obras que, con razón o sin ella, fueron escritas contra mi país y mis compatriotas: delicadeza que será respetada en lo que vale por los que tengan sentido común" (Zorrilla, 2000, p. 58).

6 Esa traición histórica no ocurrió en Tlaxcala como tal, fue en Cholula, Puebla. Hernán Cortés estuvo a punto de ser aniquilado con su tropa; sus traductores Jerónimo de Aguilar (que sobrevivió de manera increíble en la Península yucateca entre 1511-1519, era de la expedición de Juan de Valdivia, aprendió el maya) y Malinche (era una mujer muy bien preparada, se presupone era originaria de Xalisco, actual estado de Nayarit, fue regalada a Cortés en Champotón, actual estado de Campeche, hablaba el maya chontal yucateco, el náhuatl y probablemente otras lenguas originarias) escucharon de la emboscada y alertaron al conquistador (ningún originario hablaba español, lo más probable es que Marina haya sido la informante). Véanse las obras de los cronistas de indias ya referidas o la Visión de los vencidos del maestro León-Portilla (2009), en que se sintetiza estos hechos claves de la conquista.

7 Se evidencia bastante confusión de Moreno Buenvecino al indicar a Nopaltzin como contemporáneo de Xicoténcatl, ya que con base en la Historia chichimeca de Fernando de Alva Ixtlilxóchitl, este personaje fue un tlatoani del siglo XIII, hijo de Xólotl, señor principal chichimeca: "El cual estando en Tenayocan, falleció el año de mil ciento y siete de la Encarnación de Cristo Nuestro Señor, que llaman macuili Acatl: fue sepultado su cuerpo en el mismo lugar donde estaban su padre, con gran sentimiento y dolor del imperio" (de Alva Ixtlilxóchitl, 1892, p. 55). En cuanto al traidor real, se refiere que fueron dos; Tlaxcala se dividía en cuatro regiones, cada una con su señor principal o guerrero, Maxixcatzin de Ocotelulco fue el principal separatista.

8 Hay una especie de proyección de los escritores en las tramas y los personajes heroicos de sus obras, al respecto menciona Mariana Ozuna Castañeda: "Encargados durante la azarosa lucha política del México independiente de crear condiciones de gobernabilidad para realizar las ambiciones políticas y sociales del proyecto nacional, los letrados se arrojaron a esa colosal tarea con la única herramienta que poseían: la palabra escrita, cuyos atributos de orden y conocimiento la colocaron en el centro de las utopías sociales" (Ozuna Castañeda, 2012, p. 31). Y se entiende, ya que con anterioridad en el primer cotidiano de México, se buscó esa independencia cultural: "Estos miembros de la comunidad literaria piensan en una literatura nacional signada por el buen gusto al tiempo que consideran al Diario como el espacio propicio para esta misión, misión a un tiempo poética y patriótica” (Martínez Luna, 2009, p. 91). 
José Oscar luna Tolentino. La tragedia de Xicohténcatl (1823) de José María Moreno Buenvecino: rom...

9 Aunque también es necesario comentar que en la composición se vislumbra un terrible anacronismo, no solo por utilizar en los personajes principales un lenguaje y una forma de razonar castellana o esa visión teocrática prevaleciente, sino que el autor pone en voz de la princesa mexica las siguientes palabras: "De un pueblo libre. Si héroe fue Pelayo / Sublevándose audaz contra el cruel Moro, / Que había a la triste España encadenado, / ¿Por qué no ha de ser héroe Xicohténcatl / Libertando a Tlaxcala del hispano?" (Moreno Buenvecino, 1823, p. 51).

10 Fueron varios los estudiosos de la época que buscaron contradecir la historia oficial de los colonizadores que aún imperaba, por ejemplo, Manuel Orozco y Berra y Alfredo Chavero buscaron en la arqueología esas raíces. Carlos Monsiváis señala esa labor en Guillermo Prieto: "Si no con el ímpetu del Nigromante, Prieto sí rechaza sin ambages el sentido político de la dominación española (que duró "tres siglos, un mes y cuatro días"), porque entonces los mexicanos no se pertenecieron a sí mismos, privados de los derechos mínimos. [...] Del pasado indígena se rescatan a Cuitláhuac y Cuauhtémoc. Del virreinato, elogios virtuosos a las cualidades de algunos virreyes. Hay villanos: Cortés, Santa Anna, los traidores, los polkos. Y del conjunto se desprende una exigencia: activar políticamente la enseñanza histórica” (Monsiváis, 2009, p. 487).

11 Esta investigación de tres años de trabajo arduo concluyó con la publicación de dos libros intitulados: La formación de la literatura nacional (1805-1850), UNAM. 